\title{
Heterotopic ossification and clinical outcome in nonconstrained cervical arthroplasty 2 years after surgery: the Norwegian Cervical Arthroplasty Trial (NORCAT)
}

\author{
Jarle Sundseth $^{1,2}$ - Eva Astrid Jacobsen ${ }^{3}$ Frode Kolstad ${ }^{1}$ Ruth O. Sletteberg ${ }^{3}$. \\ Oystein P. Nygaard ${ }^{7,8,9} \cdot$ Lars Gunnar Johnsen ${ }^{4,5}$ - Are Hugo Pripp ${ }^{6}$. \\ Hege Andresen ${ }^{7}$ Oddrun Anita Fredriksli ${ }^{8,9} \cdot$ Erling Myrseth $^{10} \cdot$ John A. Zwart $^{3,11}$
}

Received: 20 August 2015/Revised: 23 March 2016/Accepted: 25 March 2016/Published online: 9 April 2016

(c) The Author(s) 2016. This article is published with open access at Springerlink.com

\begin{abstract}
Purpose Heterotopic ossification is a phenomenon in cervical arthroplasty. Previous reports have mainly focused on various semiconstrained devices and only a few publications have focused on ossification around devices that are nonconstrained. The purpose of this study was to assess the occurrence of heterotopic ossification around a nonconstrained cervical device and how it affects clinical outcome 2 years after surgery.

Methods Thirty-seven patients were included from a larger cohort of a randomized controlled trial (NORCAT) which compared single-level cervical arthroplasty with fusion. The occurrence of heterotopic ossification was assessed with a CT scan and two neuroradiologists determined its degree. For grading, we used the Mehren/Suchomel classification system (grade 0-4). The patients were divided by level of ossification, low grade (0-2) or high grade (3-4), and clinical outcomes were compared.
\end{abstract}

Jarle Sundseth

jsundset@ous-hf.no

1 Department of Neurosurgery, Oslo University Hospital Rikshospitalet, Postboks 4950, Nydalen, 0424 Oslo, Norway

2 Faculty of Medicine, University of Oslo, Oslo, Norway

3 Department of Neuroradiology, Oslo University Hospital Rikshospitalet, Oslo, Norway

4 National Advisory Unit of Spinal Disorders and Department of Orthopaedic Surgery, Clinic of Orthopaedics and Rheumatology, St. Olavs Hospital, Trondheim University Hospital, Trondheim, Norway

5 Department of Neuroscience, Faculty of Medicine, Norwegian University of Science and Technology, Trondheim, Norway
Self-rated disability for neck and arm pain (Neck Disability Index), health-related quality of life (the Short Form-36 and EuroQol-5D), and pain (the Numeric Rating Scale 11) were used as clinical outcome measures.

Results Heterotopic ossification was encountered in all patients 2 years after surgery. Complete fusion (grade 4) was found in $16 \%$ of participants, and high-grade ossification (grade 3-4) occurred in $62 \%$. The remaining patients were classified as having low-grade ossification (grade 2). There were no differences in the clinical outcomes of patients with low- and high-grade ossification.

Conclusion High-grade heterotopic ossification and spontaneous fusion 2 years after surgery were seen in a significant number of patients. However, the degree of ossification did not influence the clinical outcome.

Keywords Arthroplasty $\cdot$ Fusion $\cdot$ Heterotopic ossification · Cervical · Outcome
6 Department of Biostatistics, Epidemiology and Health Economics, Oslo University Hospital, Oslo, Norway

7 National Advisory Unit of Spinal Disorders, University Hospital of Trondheim (St Olavs Hospital HF), Trondheim, Norway

8 Department of Neurosurgery, University Hospital of Trondheim (St Olavs Hospital HF), Trondheim, Norway

9 University of Trondheim, Trondheim, Norway

10 Department of Neurosurgery, Haukeland University Hospital, Bergen, Norway

11 Department of Neurology and FORMI, Oslo University Hospital Ullevaal, Oslo, Norway 


\section{Introduction}

The gold standard for surgical treatment of cervical radiculopathy has been cervical discectomy and fusion (ACDF). However, studies on cervical fusion have reported an increased adjacent-level intradiscal pressure and range of motion [1-4]. The procedure has thus been perceived to accelerate adjacent segment degeneration (ASD) [5, 6]. Accordingly, the introduction of anterior cervical discectomy and arthroplasty (ACDA), which aims to preserve motion at the operated level, has gained growing interest among spinal surgeons. However, this interest is accompanied by concern with respect to heterotopic ossification (HO), a well-known phenomenon in arthroplasty of the hip and knee [7, 8]. It is also known to occur after arthroplasty in the lumbar spine, and was described and classified in this context by McAfee et al. [9]. After the introduction of cervical arthroplasty, Mehren et al. [10] published their classification system based on McAfee et al. [9]. The degree of $\mathrm{HO}$ is described as low (grade 0-2) or high (grade 3-4) [10], and in the last decade several reports have been published in which the occurrence rate of $\mathrm{HO}$ varies according to the disc prosthesis used [11-13]. Cervical arthroplasty devices are usually manufactured to be semiconstrained or nonconstrained. Semiconstrained devices allow for motion similar to normal physiological movement. Nonconstrained devices have no mechanical stop and extremes of motion are prevented by the perispinal soft tissue and inherent compression across the disc space [14]. Previously, reports regarding fusion (Mehren grade 4) have focused mainly on semiconstrained devices [15]. Few studies have assessed the occurrence of heterotopic ossification and complete fusion in cervical nonconstrained arthroplasty [16-18]. Heary et al. [16] presented a case report where complete fusion was found 5 years after surgery, and Skeppholm et al. [17] demonstrated complete fusion in $5 \%$ of their patients at an average of 40 months follow-up. The present study was realized under the framework of the Norwegian Cervical Arthroplasty Trial (NORCAT) to assess to what degree preservation of motion was maintained 2 years after surgery, and to compare our results with previous reports. In addition, we wanted to investigate if high-grade $\mathrm{HO}$ had an impact on clinical outcome compared with low-grade HO.

\section{Material and method}

\section{Study population}

NORCAT is a prospective, randomized controlled, singleblinded, multicenter trial on one-level ACDA versus ACDF. One hundred and thirty-six patients were included at five university hospitals in Norway during the time period from November 2008 to January 2013. Seventy nine out of 136 patients were included at the Department of Neurosurgery, Oslo University Hospital Rikshospitalet, Oslo, Norway. Of these, 39 were randomized to arthroplasty. Two patients had their arthroplasty device removed before 2 years follow-up due to loosening and anterior migration of the prosthesis. The present study is based on the remaining 37 patients 2 years after surgery.

Inclusion criteria were age $25-60$ years, clinical C6 or C7 root radiculopathy with corresponding radiological findings with or without neurological deficits, Neck Disability Index (NDI) $\geq 30 \%$, no response to non-operative treatment and no sign of improvement during the last 6 weeks prior to surgery.

Exclusion criteria were significant spondylosis involving more than one level, adjacent-level ankylosis, intramedullary changes on magnetic resonance imaging (MRI), clinical suspicion of myelopathy, chronic generalized pain syndrome, mental illness, infection, active cancer disease, rheumatoid arthritis involving the cervical spine, previous trauma involving the cervical spine, pregnancy, allergy to the contents of the cage/artificial disc, previous neck surgery, abuse of medication/narcotics, and that the patient did not understand oral or written Norwegian.

\section{Methods}

Computed tomography (CT) of index level was performed 2 years after surgery on all 37 patients. The CT scans were carried out with a multidetector scanner using bone algorithm, dFOV 15-18 cm, between 80 and $100 \mathrm{~mA}$ and $120 \mathrm{kV}$, and $1 \mathrm{~mm}$ increment with coronal and sagittal reconstructions. The images were evaluated twice by two experienced neuroradiologists and assessed by consensus. The radiologists were blinded with respect to clinical outcomes. To assess the degree of $\mathrm{HO}$, the Mehren classification system was used (Fig. 1) and classified as either low grade (grade 0-2) or high grade (grade 3-4).

\section{The arthroplasty device}

The arthroplasty device used in the present study was the DISCOVER $^{\circledR}$ Cervical Arthroplasty Disc Replacement System (DePuy Spine Inc., Raynham, Ma.). It is a nonconstrained device which comprises a titanium alloy superior endplate with an ultrahigh molecular weight polyethylene core that is mechanically fixed to the inferior titanium alloy endplate (Fig. 2). The hard polymer core on the inferior endplate articulates with the superior metal endplate to form a ball-and-socket type of joint. Flexionextension and axial rotation are limited by musculoligamentous restraints and the articulating surfaces. Lateral 

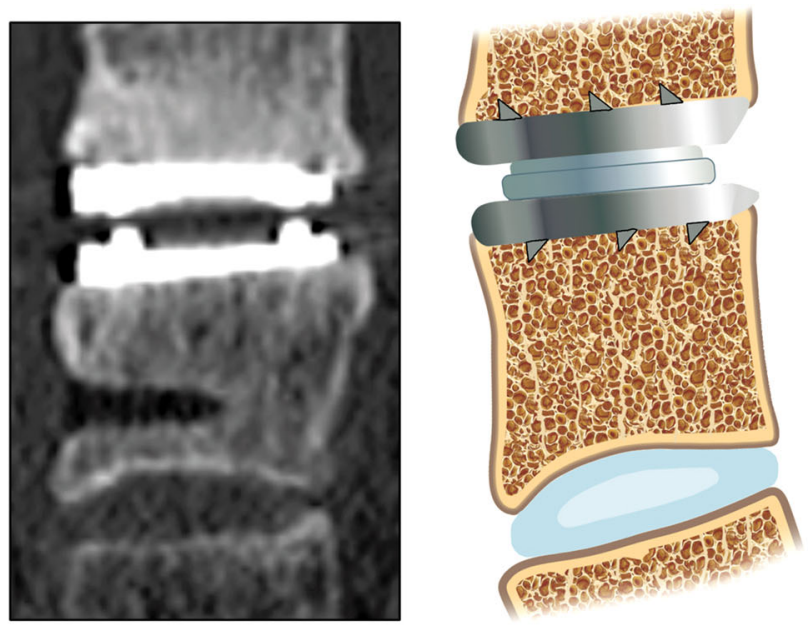

Grade $0-$ No HO present
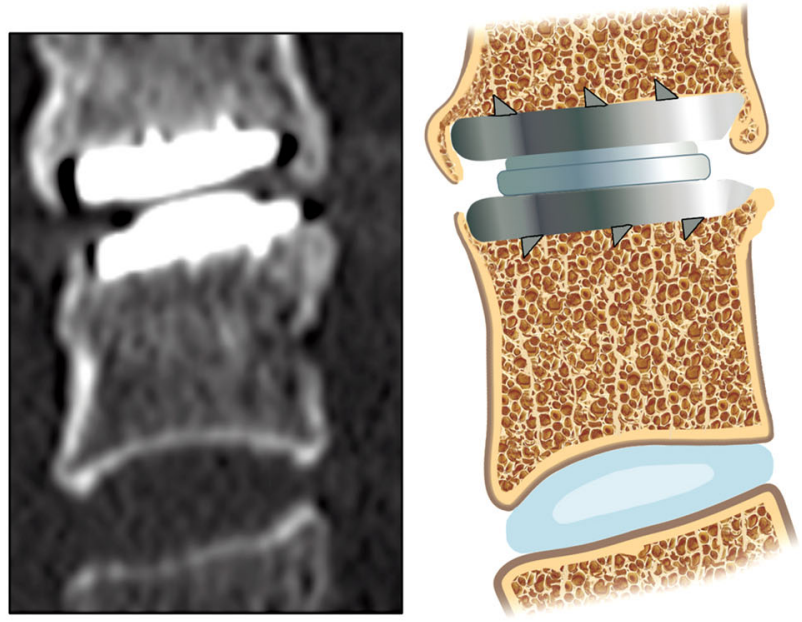

Grade II - HO is growing into the disc space, possible affection of the function of the prosthesis
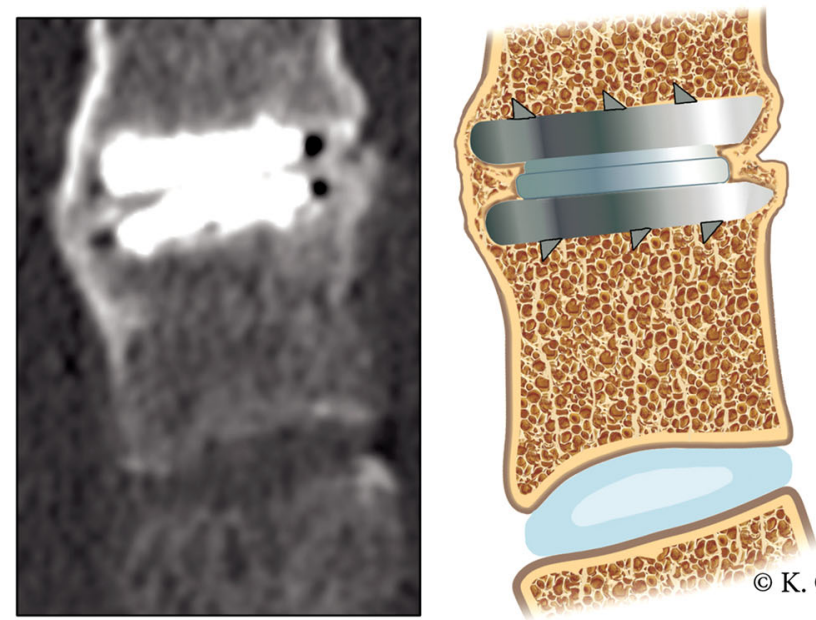

Cre K. C. Toverud
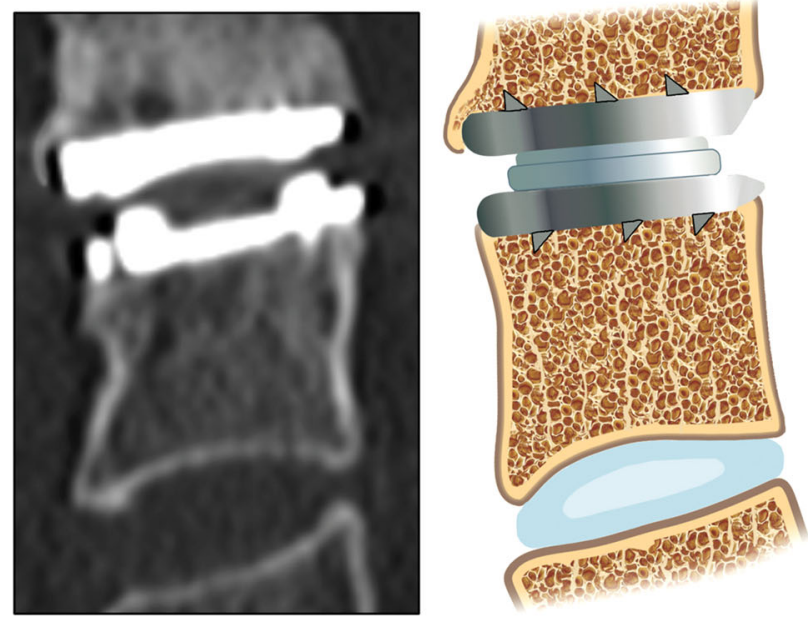

Grade I - HO is detectable in front of the vertebral body but not in the interdiscal space
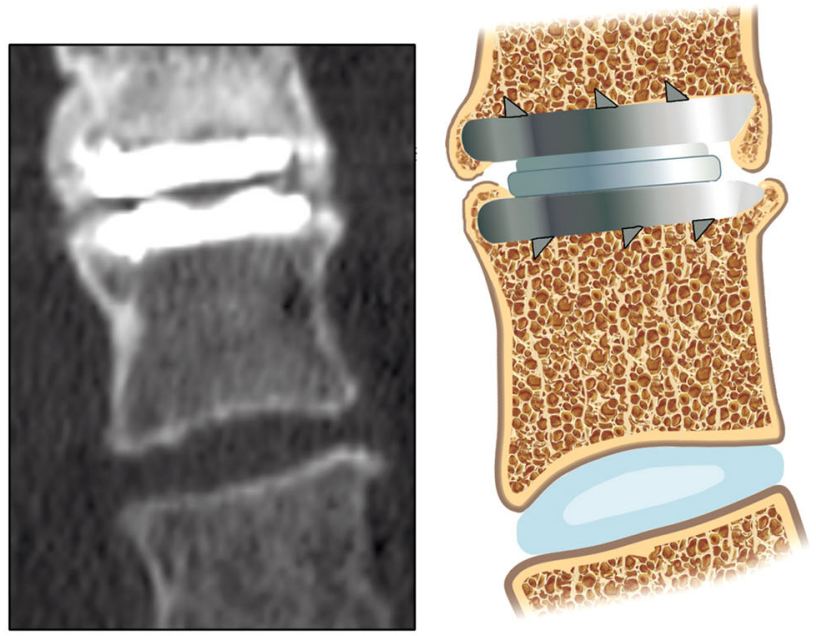

Grade III — Bridging ossifications which still allow movement of the prosthesis

Grade IV - Complete fusion of the treated segment without movement in flexion/extension

Fig. 1 The grade of heterotopic ossification (HO) was assessed using the Mehren classification system. Illustration by K. C. Toverud 


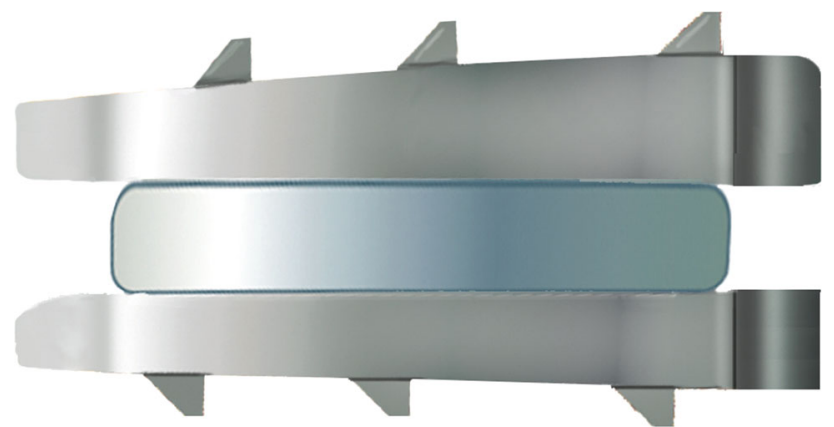

Fig. 2 Illustration of the DISCOVER ${ }^{\circledR}$ disc prosthesis (DePuy Spine Inc., Raynham, Ma.) Illustration by K. C. Toverud

motion is limited to $21^{\circ}$. The fixed inlay in combination with a ball-and-socket superior articulation with limited lateral motion has resulted in the device being described as minimally constrained [19].

\section{The surgical procedure}

A standard discectomy via the anterolateral approach was performed. The posterior longitudinal ligament was opened to visualize the dura mater and the nerve roots were decompressed. The endplates were trimmed with a diamond burr. A fluoroscope was used to ensure that the prosthesis was placed in the midline and sufficiently close to the posterior edge of the vertebra. The appropriate size of the prosthesis was determined with the use of templates.

\section{Clinical outcome and baseline variables}

\section{Primary outcome measure}

The primary outcome was the NDI [20], which is a selfrated disability score of neck and arm pain. It is composed of ten items: pain, personal care, lifting, reading, headache, concentration, work/daily activities, driving, sleep, and recreation. Each item is scored from 0 to 5. The score was calculated in percentage where higher scores represent worse function.

\section{Secondary outcome measures}

1. The Short Form-36 (SF-36) [21] is a generic healthrelated quality of life questionnaire that measures along eight dimensions: physical function, role limitations due to physical problems, bodily pain, general health, vitality, social function, role limitations due to emotional problems, and mental health. There are two summary measures: Physical Component Summary (PCS) and Mental Component Summary (MCS).of four to six items and score ranges from 0 to 100 , where a higher score is related to better health. We used the Norwegian (chronic) version v 2.0 [22], and for scoring the questionnaire, we used QualityMetric Health Outcomes Scoring Software 2.0 (QualityMetric Incorporated, Lincoln, USA).

2. The EuroQol-5 Dimension-3 level (EQ-5D-3L) [23] questionnaire is applicable to a wide range of health conditions and treatments, and provides a simple descriptive profile and a single index value for health status. The calculated index ranges from -0.59 to 1 , where a higher score represents better health. For conversion to utilities, we used the time trade-off method (TTO) and the UK tarif [24].

3. The Numeric Rating Scale 11 (NRS 11) [25] is a onedimensional pain scale from 0 to 10 where the two extreme categories are labeled "no pain at all" and "worst imaginable pain". It was used for the description of arm and neck pain.

\section{Statistics}

Continuous data are described as mean and standard deviation (SD) or median and interquartile range (IQR) as appropriate, and were statistically tested between the groups with independent $T$ test or Mann-Whitney $U$ tests depending on assumptions on statistical distribution. Categorical data are described as number of patients and percentage, and were tested with Pearson Chi-square tests or Fischer exact tests as appropriate. To assess differences in baseline characteristics between patients with low- and high-grade $\mathrm{HO}$, the demographics and baseline outcome measures were analyzed. The level of significance was defined as a $p$ value $<0.05$. SPSS version 18.0 (IBM Corporation, Armonk, New York) was used for all analysis.

\section{Ethical considerations}

The Regional Committee for Medical and Health Research Ethics and the data protection official for research approved the study. The study is registered at clinicaltrials.gov [26]. All patients included in the trial gave their written informed consent to participate.

\section{Results}

The mean age at inclusion was 44 years (range $33-59$ years). Twenty patients $(54.1 \%)$ were female. The disc level $\mathrm{C} 5 / \mathrm{C} 6$ was operated in $59.5 \%$ and $\mathrm{C} 6 / \mathrm{C} 7$ in $40.5 \%$. There were no statistically significant differences in baseline characteristics between patients with low- and high-grade HO (Table 1). HO was encountered in all 
Table 1 Baseline characteristics of the patients with low- and highgrade HO 2 years after surgery

\begin{tabular}{lccc}
\hline & $\begin{array}{l}\text { Low grade } \\
\text { Mehren 0-2 } \\
N=14\end{array}$ & $\begin{array}{l}\text { High grade } \\
\text { Mehren 3-4 }\end{array}$ & $p=23$ \\
& $44.9(7.4)$ & $43.7(6.7)$ & 0.63 \\
\hline Age, years $( \pm$ SD) & $9(64.3)$ & $11(47.8)$ & 0.40 \\
Female sex, no. $(\%)$ & $170.4(10.6)$ & $174.3(10.1)$ & 0.29 \\
Heights, cm $( \pm \mathrm{SD})$ & $72.1(11.3)$ & $81.7(18.1)$ & 0.09 \\
Weight, kg $( \pm \mathrm{SD})$ & $25.6(2.7)$ & $26.5(4.1)$ & 0.52 \\
Body-mass index ${ }^{\mathrm{a}}( \pm \mathrm{SD})$ & $10(71.4)$ & $12(52.2)$ & 0.14 \\
Level operated C5/C6 $(\%)$ & $49.0(15.0)$ & $46.4(12.5)$ & 0.57 \\
NDI $( \pm$ SD) & $0.30(0.29)$ & $0.34(0.35)$ & 0.70 \\
EQ-5D $( \pm$ SD) & $36.5(5.7)$ & $34.2(7.8)$ & 0.36 \\
SF-36 PCS $( \pm$ SD) & $42.1(11.5)$ & $48.5(11.1)$ & 0.11 \\
SF-36 MCS $( \pm$ SD) & $6.5(5-10)$ & $6.5(3-10)$ & 0.34 \\
NRS neck pain, median $(I Q R)$ & $7(3-10)$ & $5(0-10)$ & 0.33 \\
NRS arm pain, median $(I Q R)$ & &
\end{tabular}

a The body mass index is weight in kilograms divided by the square of the height in meters

Table 2 Distribution of patients according to the HO grade

\begin{tabular}{llllll}
\hline $\begin{array}{l}\text { HO } \\
\text { grade }\end{array}$ & 0 & 1 & 2 & 3 & 4 \\
\hline$N(\%)$ & 0 & 0 & $\begin{array}{c}14 \\
(37.8)\end{array}$ & $\begin{array}{c}17 \\
(45.9)\end{array}$ & $6(16.3)$ \\
\hline
\end{tabular}

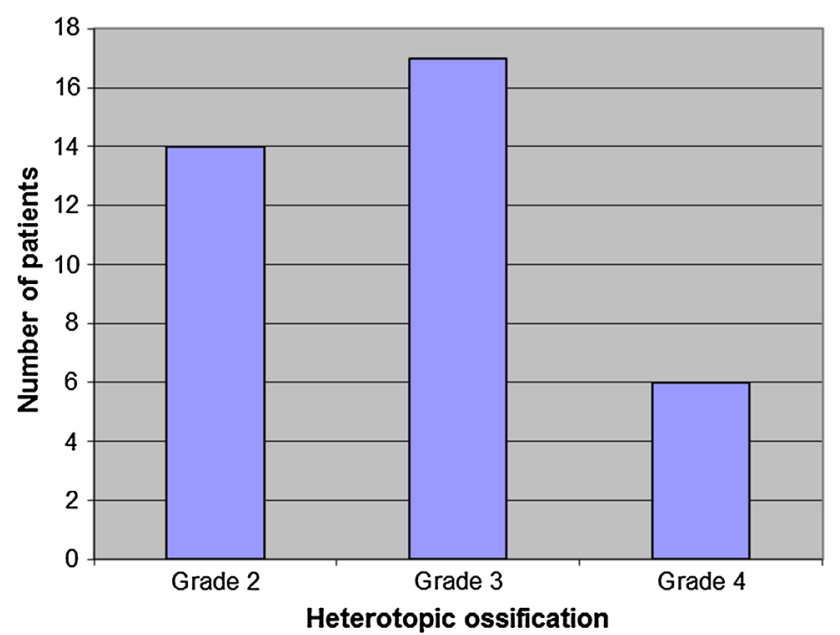

Fig. 3 Distribution of heterotopic ossification (HO) 2 years after surgery. Classification from 0 (no HO) to 4 (fusion) according to Mehren [10]. No patients were classified as Mehren grade 0 or 1

patients 2 years after surgery. Twenty-three patients $(62.2 \%)$ had developed high-grade $\mathrm{HO}$ and complete fusion was found in six $(16.3 \%)$. The remaining 14 patients $(37.8 \%)$ were classified as grade 2 (Table 2; Fig. 3).

At 2 years follow-up, NDI scores $( \pm \mathrm{SD})$ in patients with low- and high-grade HO were $27.0( \pm 19.6)$ and 26.8

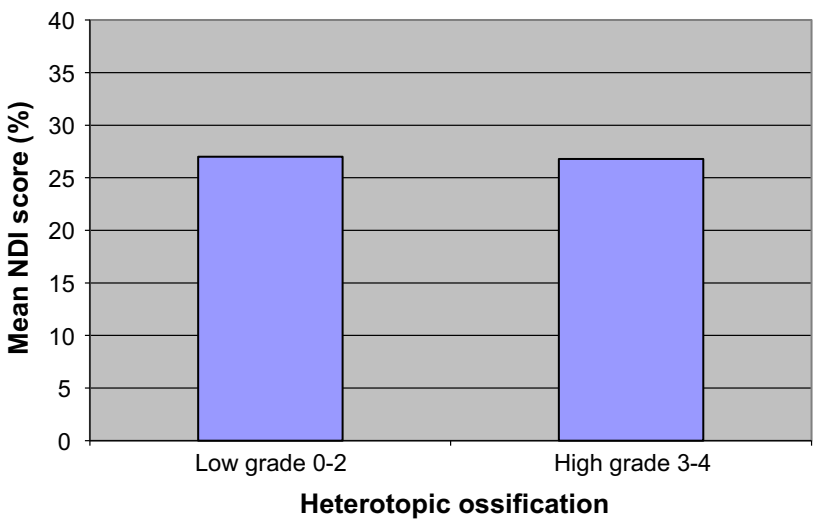

Fig. 4 Primary clinical outcome measure, the Neck Disability Index between patients with low- and high-grade HO 2 years after surgery

( \pm 20.3 ), respectively (Fig. 4). The difference was not statistically significant, $p=0.98$; nor were there any significant differences in any of the secondary clinical outcome measures (Table 3).

There were no major perioperative complications. However, out of 39 patients who were randomized to arthroplasty at the Oslo University Hospital, Rikshospitalet, 2 patients $(5.1 \%)$ had undergone index level reoperation before 2 years follow-up, leaving 37 patients in the present study. The reason for additional surgical treatment was due to loosening and anterior displacement of the arthroplasty device. Reoperations were performed with removal of the prosthesis, followed by fusion with cage and anterior plating.

\section{Discussion}

Cervical arthroplasty aims to preserve motion, but heterotopic ossification is an undesirable phenomenon in arthroplasty surgery which may cause reduced or absent mobility at the operated level. The objective of this study was to investigate the occurrence of heterotopic ossification 2 years after arthroplasty surgery, and to assess if the degree of ossification had an impact on the clinical outcome. The study was realized under the framework of the Norwegian Cervical Arthroplasty Trial.

Trial limitations are the number of patients included, which preclude firm conclusions about the study results. Further, the images were evaluated by two neuroradiologists by consensus and not as interobserver variation with kappa statistics.

$\mathrm{HO}$ was found in all patients 2 years after surgery. Highgrade $\mathrm{HO}$ was found in $62.2 \%$ of the patients and a complete fusion in $16.3 \%$. There were, however, no significant differences in either the primary or secondary outcome measures between patients with low- and highgrade $\mathrm{HO}$. 
Table 3 Clinical outcome for low- and high-grade $\mathrm{HO} 2$ years after surgery

\begin{tabular}{lllcl}
\hline Mehren grade & $\begin{array}{l}\text { Low grade 0-2 } \\
N=14\end{array}$ & $\begin{array}{l}\text { High grade 3-4 } \\
N=23\end{array}$ & $\begin{array}{l}\text { Low grade-high grade } \\
\text { mean difference }(95 \% \text { CI }\end{array}$ & $p$ \\
\hline NDI $( \pm$ SD) & $27.0(19.6)$ & $26.8(20.3)$ & $0.2(-14.7$ to 15.2$)$ & 0.98 \\
EQ-5D $( \pm$ SD) & $0.76(0.28)$ & $0.68(0.35)$ & $0.08(-0.16$ to 0.33$)$ & 0.49 \\
SF-36 PCS $( \pm$ SD) & $48.4(9.5)$ & $49.6(11.0)$ & $-1.2(-8.7$ to 6.4$)$ & 0.76 \\
SF-36 MCS $( \pm$ SD) & $53.8(14.2)$ & $48.9(14.3)$ & $4.9(-5.4$ to 15.1$)$ & 0.34 \\
NRS neck pain, median $(I Q R)$ & $3(0.25-6)$ & $4.5(0.25-7.75)$ & & 0.74 \\
NRS arm pain, median $(I Q R)$ & $2.5(0-6.75)$ & $1.5(0.25-4)$ & & 0.45 \\
\hline
\end{tabular}

HO around cervical disc prostheses has been reported with both semiconstrained and nonconstrained devices [11-13, 15, 18]. However, the occurrence of complete fusion (grade 4) with nonconstrained devices is rare. Tu et al. [18] have previously reported this phenomenon with the Bryan cervical disc (Medtronic Spine and Biologics). Recently, it was also assessed in one clinical trial and in one case report using the same arthroplasty device as in the present study [16, 17].

A possible mechanism for $\mathrm{HO}$ development is related to increased height and range of motion (ROM) of the operated level [27]. Devices that are nonconstrained, as used in the present trial, cannot stop motion mechanically and are reliant on perispinal soft tissue and compression across the disc space to hinder extreme motion. Compared with other studies, the occurrence of $\mathrm{HO}$ in the present trial was higher than previously reported [10-13, 18, 28]. Zhou et al. [11] included nine studies in their meta-analysis of $\mathrm{HO}$ in both semiconstrained and nonconstrained devices. In six of the studies, nonconstrained implants were used. Follow-up ranged from 24 to 96 months and the occurrence of $\mathrm{HO}$ ranged from 37.5 to $62 \%$. An early study of $\mathrm{HO}$ with the Bryan Cervical Disc [12] found that $17.8 \%$ of the patients had developed HO 12 months after surgery. Yi et al. [13] assessed $\mathrm{HO}$ after 20 months in both nonconstrained and semiconstrained devices. With the nonconstrained devices, Bryan and Mobi-C (LDR Medical, Troyes, France), HO was found in 21.0 and $52.5 \%$, respectively. With the semiconstrained device, ProDisc-C (Synthes, Inc., West Chester, PA), HO was found in $71.4 \%$. Skeppholm et al. [17] used the same arthroplasty device as in the present study and found that HO caused complete fusion and very limited motion in 5 and $8 \%$, respectively, after 40 months. On the other hand, Qizhi et al. [29], who used the Discover device in two-level disc surgery, found no $\mathrm{HO}$ after 32,4 months. Tu et al. [18] reported $50 \% \mathrm{HO}$ with the Bryan device at a mean 19 months follow-up, and Suchomel et al. [28] found high-grade $\mathrm{HO}$ in $63 \%$ after 4 years with the ProDisc-C. Thus, different degrees of constraints seem to influence the development of $\mathrm{HO}$, but $\mathrm{HO}$ also differs among devices with the same degree of constraint and in different reports concerning the same device. In the present study, HO occurred in all implanted devices and the degree of high-grade HO was approximately the same as reported by Suchomel et al. [28], but in a much shorter observation period. Possible explanations can be related to implant design, suboptimal implantation of the prosthesis, incorrect size of the device, or the individual surgical technique, even though all surgeons had good experience with the particular arthroplasty device.

A recent meta-analysis comparing multi-level and single-level ACDA found that the occurrence of $\mathrm{HO}$ did not depend on the number of levels operated on [30]. The presence of $\mathrm{ASD}$, on the other hand, has recently been found to significantly correlate with the development of HO [31].

Park et al. found that surgical technique influenced the development of HO [32]. In their study, two surgeons performed all operations; however, they had different techniques for trimming endplates. One surgeon used a fluted ball-type burr, while the other used a diamond-type burr. The study found that the use of fluted ball-type burr resulted in significantly more HO. In the present study, only diamond burrs were used to trim the endplates. Nevertheless, HO was seen in all patients 2 years after surgery.

Several other possible causal factors regarding $\mathrm{HO}$ have been discussed, such as not treating patients with nonsteroidal anti-inflammatory drugs (NSAIDs) after surgery. The use of NSAIDs to prevent $\mathrm{HO}$ after total hip replacement has been reported previously [33]. The study protocols of clinical trials for cervical arthroplasty undertaken by the US Food and Drug Administration included the perioperative use of NSAIDs as an attempt to prevent the occurrence of $\mathrm{HO}$. One study has reported a trend toward decreased $\mathrm{HO}$ formation in patients who used NSAIDs after cervical disc arthroplasty compared with those who did not, but the difference was not statistically significant [34]. NSAIDs were not used routinely in the present trial and further studies should assess the role of NSAIDs in the development of $\mathrm{HO}$ after cervical disc arthroplasty.

Other predisposing factors that have been discussed are age and gender. Male gender has previously been reported to correlate with $\mathrm{HO}$ formation [35] and could be a 
contributing factor regarding the observed difference in HO occurrence compared with other reports. However, the present male/female ratio was not much different from the other studies. There was no relationship between high- and low-grade $\mathrm{HO}$ and age or gender in the present study.

Motion between two vertebrae occurs around a point described as instantaneous axis of rotation (IAR). The IAR is commonly located in the posterior half of the upper portion of the inferior vertebral body, the central region of the intervertebral disc, or the middle region of the subjacent vertebrae. However, there is not one axis of rotation in the cervical spine. The IAR identifies the rotation of one vertebra relative to another at a given point in time and will change when the motion of the vertebral body consists of both a translational and a rotational component. Artificial cervical discs should have an axis of rotation that mimics the kinematics of the normal spine to restore the physiologic range of motion and disc height and to transmit axial loading forces from the superior to the inferior vertebral body [36]. Some arthroplasty devices, like the DISCOVER $^{\circledR}$ and the ProDisc-C, have a ball-and-socket single-articulating design with a fixed center of rotation (COR). With such devices, a posterior positioning of the implant in the disc space is important. Others, like the Bryan prosthesis, have double articulation surfaces and independent translation, which allows for a mobile COR. With a mobile COR, various positions of the device may theoretically maintain physiologic kinematics. Whether an altered COR due to implantation of an arthroplasty device has clinical consequences in the long term is not yet known. However, an imprecise position of the implant may cause a negatively altered COR and perhaps influence $\mathrm{HO}$ formation. Assuming that replication of a physiologic COR is an important design feature of a cervical prosthesis, Koller et al. found that ideal surgical preparation and ideal positioning of the implant are most important to preserve the segmental COR and balance [19].

Although the difference in $\mathrm{HO}$ formation was considerable, the grade of $\mathrm{HO}$ did not influence the clinical outcome in the present trial. However, our results do not correspond with the findings of a recent meta-analysis where patients with high-grade $\mathrm{HO}$ felt significantly less pain than patients with low-grade HO [10]. The same study also concluded that the presence of $\mathrm{HO}$ did not influence the clinical outcome.

Fusion naturally prevents motion, and very limited motion has recently been shown with HO [17]. Based on the results from the present trial, it seems that the benefit of cervical disc arthroplasty, namely preservation of physiological motion, is of limited relevance with respect to the clinical outcome. This is consistent with previous results regarding arthroplasty in the lumbar spine [37].

\section{Conclusion}

High-grade $\mathrm{HO}$ and spontaneous fusion 2 years after surgery were seen in a significant number of patients, but the degree of ossification did not influence the clinical outcome. However, conclusion about the effect of $\mathrm{HO}$ on the development of adjacent-level degeneration and clinical outcome in the long term, cannot be drawn. Trials with even longer follow-up are needed for more definite answers concerning $\mathrm{HO}$ and its impact on mobility as well as clinical outcome. The main goal of cervical arthroplasty is preservation of motion, which for a significant number of patients in the present study was not achieved with the device under the applied surgical techniques used in the NORCAT.

Acknowledgments The study was supported by the South-Eastern Norway Regional Health Authority (grant number 2012009). The authors would like to thank Vigdis Skogli, Torun Gillebo, Jorund Roos, Camilla Seif and Monica Finkirk for their efforts in assembling patients, coordination of investigations and follow-up of the study.

\section{Compliance with ethical standards}

Conflict of interest The study committee received a grant from DePuy Synthes Spine (325 Paramount Drive Raynham, MA 02767) which made it possible for the project to be completed. The study sponsor was not involved in the study design, conduction of the trial or the writing or review of the manuscript. The prostheses implanted were solely financed by the individual hospitals.

Open Access This article is distributed under the terms of the Creative Commons Attribution 4.0 International License (http://crea tivecommons.org/licenses/by/4.0/), which permits unrestricted use, distribution, and reproduction in any medium, provided you give appropriate credit to the original author(s) and the source, provide a link to the Creative Commons license, and indicate if changes were made.

\section{References}

1. Weinhoffer SL, Guyer RD, Herbert M, Griffith SL (1995) Intradiscal pressure measurements above an instrumented fusion. A cadaveric study. Spine 20:526-531

2. Fuller DA, Kirkpatrick JS, Emery SE, Wilber RG, Davy DT (1998) A kinematic study of the cervical spine before and after segmental arthrodesis. Spine 23:1649-1656

3. Eck JC, Humphreys SC, Lim TH, Jeong ST, Kim JG, Hodges SD, An HS (2002) Biomechanical study on the effect of cervical spine fusion on adjacent-level intradiscal pressure and segmental motion. Spine 27:2431-2434. doi:10.1097/01.brs.0000031261.66972.b1

4. Chang UK, Kim DH, Lee MC, Willenberg R, Kim SH, Lim J (2007) Changes in adjacent-level disc pressure and facet joint force after cervical arthroplasty compared with cervical discectomy and fusion. J Neurosurg Spine 7:33-39. doi:10.3171/spi-07/ $07 / 033$

5. Hilibrand AS, Robbins M (2004) Adjacent segment degeneration and adjacent segment disease: the consequences of spinal fusion? Spine J Off J North American Spine Soc 4:190s-194s. doi:10. 1016/j.spinee.2004.07.007 
6. Litrico S, Lonjon N, Riouallon G, Cogniet A, Launay O, Beaurain J, Blamoutier A, Pascal-Mousselard H (2014) Adjacent segment disease after anterior cervical interbody fusion. A multicenter retrospective study of 288 patients with long-term followup. Orthop Traumatol Surg Res OTSR 100:S305-S309. doi:10. 1016/j.otsr.2014.07.004

7. Rama KR, Vendittoli PA, Ganapathi M, Borgmann R, Roy A, Lavigne M (2009) Heterotopic ossification after surface replacement arthroplasty and total hip arthroplasty: a randomized study. J Arthr 24:256-262. doi:10.1016/j.arth.2007.12.004

8. Dalury DF, Jiranek WA (2004) The incidence of heterotopic ossification after total knee arthroplasty. J Arthr 19:447-452

9. McAfee PC, Cunningham BW, Devine J, Williams E, Yu-Yahiro J (2003) Classification of heterotopic ossification (HO) in artificial disk replacement. J Spinal Disord Tech 16:384-389

10. Zhou HH, Qu Y, Dong RP, Kang MY, Zhao JW (2015) Does heterotopic ossification affect the outcomes of cervical total disc replacement? A meta-analysis. Spine 40:E332-E340. doi:10. 1097/brs.0000000000000776

11. Leung C, Casey AT, Goffin J, Kehr P, Liebig K, Lind B, Logroscino C, Pointillart V (2005) Clinical significance of heterotopic ossification in cervical disc replacement: a prospective multicenter clinical trial. Neurosurgery 57:759-763 (discussion 759-763)

12. Yi S, Kim KN, Yang MS, Yang JW, Kim H, Ha Y, Yoon DH, Shin HC (2010) Difference in occurrence of heterotopic ossification according to prosthesis type in the cervical artificial disc replacement. Spine 35:1556-1561. doi:10.1097/BRS. 0b013e3181c6526b

13. Heidecke V, Burkert W, Brucke M, Rainov NG (2008) Intervertebral disc replacement for cervical degenerative diseaseclinical results and functional outcome at 2 years in patients implanted with the Bryan cervical disc prosthesis. Acta neurochirurgica 150:453-459. doi:10.1007/s00701-008-1552-7 (discussion 459)

14. Puttlitz CM, DiAngelo DJ (2005) Cervical spine arthroplasty biomechanics. Neurosurg Clin North Am 16:589-594. doi:10. 1016/j.nec.2005.07.002

15. Mehren C, Suchomel P, Grochulla F, Barsa P, Sourkova P, Hradil J, Korge A, Mayer HM (2006) Heterotopic ossification in total cervical artificial disc replacement. Spine 31:2802-2806. doi:10. 1097/01.brs.0000245852.70594.d5

16. Heary RF, Goldstein IM, Getto KM, Agarwal N (2014) Solid radiographic fusion with a nonconstrained device 5 years after cervical arthroplasty. J Neurosurg Spine 21:951-955. doi:10. 3171/2014.8.spine14101

17. Skeppholm M, Svedmark P, Noz ME, Maguire GQ, Jr., Olivecrona H, Olerud C (2015) Evaluation of mobility and stability in the Discover artificial disc: an in vivo motion study using highaccuracy 3D CT data. J Neurosurg Spine 23:383-389. doi:10. 3171/2014.12.spine 14813

18. Tu TH, Wu JC, Huang WC, Guo WY, Wu CL, Shih YH, Cheng $\mathrm{H}$ (2011) Heterotopic ossification after cervical total disc replacement: determination by $\mathrm{CT}$ and effects on clinical outcomes. J Neurosurg Spine 14:457-465. doi:10.3171/2010.11. spine 10444

19. Koller H, Meier O, Zenner J, Mayer M, Hitzl W (2013) In vivo analysis of cervical kinematics after implantation of a minimally constrained cervical artificial disc replacement. Eur Spine J off Publ Eur Spine Soc Eur Spinal Deform Soc Eur Sect Cerv Spine Res Soc 22:747-758. doi:10.1007/s00586-012-2583-6

20. Vernon H, Mior S (1991) The Neck Disability Index: a study of reliability and validity. J Manip Physiol Ther 14:409-415

21. Ware JE Jr, Sherbourne CD (1992) The MOS 36-item short-form health survey (SF-36). I. Conceptual framework and item selection. Med Care 30:473-483
22. Loge JH, Kaasa S (1998) Short form 36 (SF-36) health survey: normative data from the general Norwegian population. Scand J Soc Med 26:250-258

23. Brooks RG, Jendteg S, Lindgren B, Persson U, Bjork S (1991) EuroQol: health-related quality of life measurement. Results of the Swedish questionnaire exercise. Health Policy (Amsterdam, Netherlands) 18:37-48

24. EuroQol Group (1990) EuroQol-a new facility for the measurement of health-related quality of life. Health Policy 16:199-208

25. Downie WW, Leatham PA, Rhind VM, Wright V, Branco JA, Anderson JA (1978) Studies with pain rating scales. Ann Rheum Dis 37:378-381

26. ClinicalTrials.gov (2015) NCT00735176. ClinicalTrials.gov. 2015

27. Su Kim K, Hwa Heo D (2013) Do postoperative biomechanical changes induce heterotopic ossification after cervical arthroplasty? A 5-year follow-up study. J Spinal Disord Tech. doi:10. 1097/bsd.0000000000000054

28. Suchomel P, Jurak L, Benes V 3rd, Brabec R, Bradac O, Elgawhary S (2010) Clinical results and development of heterotopic ossification in total cervical disc replacement during a 4-year follow-up. Eur Spine J Off Publ Eur Spine Soc Eur Spinal Deform Soc Eur Sect Cerv Spine Res Soc 19:307-315. doi:10. 1007/s00586-009-1259-3

29. Qizhi S, Lei S, Peijia L, Hanping Z, Hongwei H, Junsheng C, Jianmin L (2016) A comparison of zero-profile devices and artificial cervical disks in patients with 2 noncontiguous levels of cervical spondylosis. Clin Spine Surg 29:E61-E66. doi:10.1097/ bsd.0000000000000096

30. Zhao H, Cheng L, Hou Y, Liu Y, Liu B, Mundra JJ, Nie L (2015) Multi-level cervical disc arthroplasty (CDA) versus single-level CDA for the treatment of cervical disc diseases: a meta-analysis. Eur Spine J Off Publ Eur Spine Soc Eur Spinal Deform Soc Eur Sect Cerv Spine Res Soc 24:101-112. doi:10.1007/s00586-014-3429-1

31. Lee SE, Jahng TA, Kim HJ (2015) Correlation between cervical lordosis and adjacent segment pathology after anterior cervical spinal surgery. Eur Spine J Off Publ Eur Spine Soc Eur Spinal Deform Soc Eur Sect Cerv Spine Res Soc 24:2899-2909. doi:10. 1007/s00586-015-4132-6

32. Park JH, Rhim SC, Roh SW (2013) Mid-term follow-up of clinical and radiologic outcomes in cervical total disk replacement (Mobi-C): incidence of heterotopic ossification and risk factors. J Spinal Disord Tech 26:141-145. doi:10.1097/BSD. 0b013e31823ba071

33. Sodemann B, Persson PE, Nilsson OS (1988) Prevention of heterotopic ossification by nonsteroid antiinflammatory drugs after total hip arthroplasty. Clin Orthop Relat Res 237:158-163

34. Tu TH, Wu JC, Huang WC, Chang HK, Ko CC, Fay LY, Wu CL, Cheng H (2015) Postoperative nonsteroidal antiinflammatory drugs and the prevention of heterotopic ossification after cervical arthroplasty: analysis using CT and a minimum 2-year follow-up. J Neurosurg Spine 22:447-453. doi:10.3171/2014.10.spine14333

35. Yi S, Shin DA, Kim KN, Choi G, Shin HC, Kim KS, Yoon DH (2013) The predisposing factors for the heterotopic ossification after cervical artificial disc replacement. Spine J Off J North Am Spine Soc 13:1048-1054. doi:10.1016/j.spinee.2013.02.036

36. Jaramillo-de la Torre JJ, Grauer JN, Yue JJ (2008) Update on cervical disc arthroplasty: where are we and where are we going? Curr Rev Musculoskelet Med 1:124-130. doi:10.1007/s12178008-9019-2

37. Johnsen LG, Brinckmann P, Hellum C, Rossvoll I, Leivseth G (2013) Segmental mobility, disc height and patient-reported outcomes after surgery for degenerative disc disease: a prospective randomised trial comparing disc replacement and multidisciplinary rehabilitation. Bone Joint J 95-b:81-89. doi:10.1302/ 0301-620x.95b1.29829 